\title{
Topical Diclofenac, an Efficacious Treatment for Osteoarthritis: A Narrative Review
}

Frédérique Bariguian Revel · Marina Fayet · Martina Hagen

Received: December 19, 2019 / Published online: February 21, 2020

(C) The Author(s) 2020

\begin{abstract}
Multiple head-to-head trials have demonstrated that topical nonsteroidal anti-inflammatory drugs (NSAIDs), including topical diclofenac, provide at least equivalent analgesia, improvement in physical function, and reduction of stiffness compared with oral NSAIDs in osteoarthritis and have fewer systemic adverse events. While efficacy of topical diclofenac in osteoarthritis is well established, understanding of the time to onset of action, duration of effect, and the minimum effective concentration is limited. Factors likely to influence these parameters include drug penetration and localization. Diclofenac concentrations in the joint tissues are likely to be more relevant than plasma concentrations. However, although
\end{abstract}

Enhanced Digital Features To view enhanced digital features for this article go to: https://doi.org/10.6084/ m9.figshare.11791470.

Electronic supplementary material The online version of this article (https://doi.org/10.1007/s40744020-00196-6) contains supplementary material, which is available to authorized users.

F. Bariguian Revel $(\bowtie) \cdot$ M. Fayet · M. Hagen $(\bowtie)$ GSK Consumer Healthcare S.A, Route de l'Etraz 2, 1260 Nyon, Switzerland

e-mail: frederique.j.bariguian-revel@gsk.com

M. Hagen

e-mail: martina.x.hagen@gsk.com diclofenac penetrates and is retained in these "effect compartments" at the site of inflammation and drug activity, no specific minimum effective concentration of diclofenac in plasma or synovial tissue has been identified. Recent evidence suggests that a reduction in inflammatory markers may be a better predictor of efficacy than plasma concentrations. This narrative review explores existing evidence in these areas and identifies the gaps where further research is needed. Based on our findings, topical NSAIDs such as diclofenac should be considered as a guideline-supported, generally well-tolerated, and effective first-line treatment option for knee and hand OA, especially for older patients and those who have comorbid conditions and/or risk factors for various systemic (gastrointestinal, hepatic, renal, or cardiovascular) adverse events associated with oral NSAIDs, particularly at high doses and with long-term use.

Keywords: Anti-inflammatory agents; Arthralgia; Chronic pain; Diclofenac; Nonsteroidal; Osteoarthritis 


\section{Key Summary Points}

Topical diclofenac relieves osteoarthritis (OA) pain and stiffness and improves physical function, at least to the same degree as some oral NSAIDs, with fewer systemic side effects.

The topical route of administration may positively contribute to the perceived pain reduction in $\mathrm{OA}$.

Limited data suggest that pain relief begins within a few hours of topical administration and is generally well sustained throughout the 12-h dosing interval.

Topical diclofenac penetrates the skin, permeates underlying tissues, and enters the synovium, where it may preferentially accumulate in inflamed joint tissues and reduce prostaglandin E2 (PGE2) and various pro-inflammatory biomarkers [e.g., tumor necrosis factor alpha (TNF $\alpha$ ), interleukin-6 (IL-6), and interleukin-8 (IL8)].

However, minimum effective concentrations in the synovial tissue and synovial fluid and minimum effective reductions in PGE2 and inflammatory biomarkers have not been identified.

Topical diclofenac may be preferred over oral nonsteroidal anti-inflammatory drugs (NSAIDs), especially for older patients with $\mathrm{OA}$ and those who have comorbid conditions and/or risk factors for various systemic (gastrointestinal, hepatic, renal, or cardiovascular) adverse events associated with oral NSAIDs, particularly when used at high doses or for long durations.

\section{Clinical implications}

Topical NSAIDs such as diclofenac are an effective, guideline-supported treatment for knee and hand OA with comparable efficacy and fewer systemic side effects than some oral NSAIDs.
Topical diclofenac should be considered as a first-line option, before oral NSAID use, especially for older patients with OA and those who have comorbid conditions and/ or risk factors for various systemic (gastrointestinal, hepatic, renal, or cardiovascular) adverse events associated with oral NSAIDs, particularly when used at high doses or for long durations.

Patients with polyarticular OA can use topical NSAIDs on multiple joints concurrently but should be advised to carefully follow dosing instructions and avoid exceeding the recommended maximum daily dose across all joints treated.

Dermatologic effects (dry skin, redness at the application site, pruritus, contact dermatitis) are the most common adverse events and can be managed by product removal and symptomatic treatments if desired.

\section{INTRODUCTION}

Osteoarthritis (OA) currently affects approximately 300 million people worldwide [1]. Because risk factors for OA are known to include older age and obesity, the global prevalence and burden of disease attributable to OA are expected to increase over time $[2,3]$.

$\mathrm{OA}$ is a heterogeneous disease with a wide range of underlying pathologies that ultimately lead to joint damage [3-6]. For this reason, OA can be described as a complex syndrome rather than a single disease [7]. OA involves structural alterations in articular cartilage, subchondral bone, ligaments, joint capsule, synovial membrane, and periarticular muscle [8]. In addition to mechanical and metabolic factors, inflammation is now understood to be a key mediator of $\mathrm{OA}$ that contributes to cartilage loss and progressive degeneration of affected joints $[9,10]$. Preclinical investigations have 
demonstrated that abnormal mechanical joint stress is converted into activated intracellular signaling, leading to downstream overexpression of inflammatory mediators such as prostaglandins, chemokines, and cytokines [11-13]. Thus, OA is no longer considered a noninflammatory arthritis or a "wear and tear" disease $[9,10]$.

OA-related joint destruction and inflammation cause pain, which contributes to functional limitations, increased healthcare resource utilization, and reduced quality of life in patients with this condition $[5,14,15]$. National and international English-language guidelines for the treatment of OA uniformly support a role for nonsteroidal anti-inflammatory drugs (NSAIDs) for pain management in patients with OA (described and referenced in Supplementary Table 1). Of 24 such guidelines, 19 endorse the use of topical NSAIDs as a treatment option for OA pain. The most recent such guideline, the 2019 American College of Rheumatology and Arthritis Foundation guideline for management of OA of the hand, hip, and knee, strongly recommends topical NSAIDs for knee OA, conditionally recommends them for hand OA, and further notes that topical NSAIDs should be used prior to oral NSAIDs on the basis that it is preferable to use medications with the least systemic exposure [16].

Topical diclofenac is absorbed through the skin and penetrates into subdermal tissues, including synovial tissue, to act directly at the site of pain and inflammation [17]. By inhibiting predominantly cyclooxygenase $2(\mathrm{COX}-2)$ enzymes $\left(\mathrm{COX}-1 / \mathrm{COX}-2 \mathrm{IC}_{50}\right.$ ratio $=29$ [18]) which are responsible for converting arachidonic acid into prostaglandins, thromboxanes, and prostacyclins [19]—diclofenac reduces prostaglandin production (Fig. 1 [19-26]), thereby limiting prostaglandin-related sensitization of peripheral nociceptors to painful/mechanical stimuli [27]. In this review, we survey studies of topical diclofenac's efficacy, tolerability, and pharmacokinetic/pharmacodynamic properties in OA, and identify areas where additional research is needed.

\section{METHODS}

For this narrative review, we conducted three literature searches related to the general efficacy of topical diclofenac in OA, the onset and duration of analgesia, and the minimum

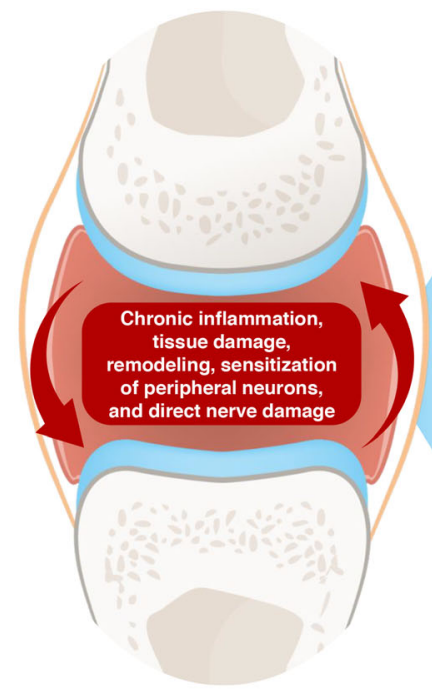

Fig. 1 NSAID modulation of COX-2 and NFאB pathways leads to decreases in PGE2 plasma levels and proinflammatory cytokines [19-26]. COX-1 and COX-2, cycolooxygenase-1 and -2; EP2 and EP4, two of the four

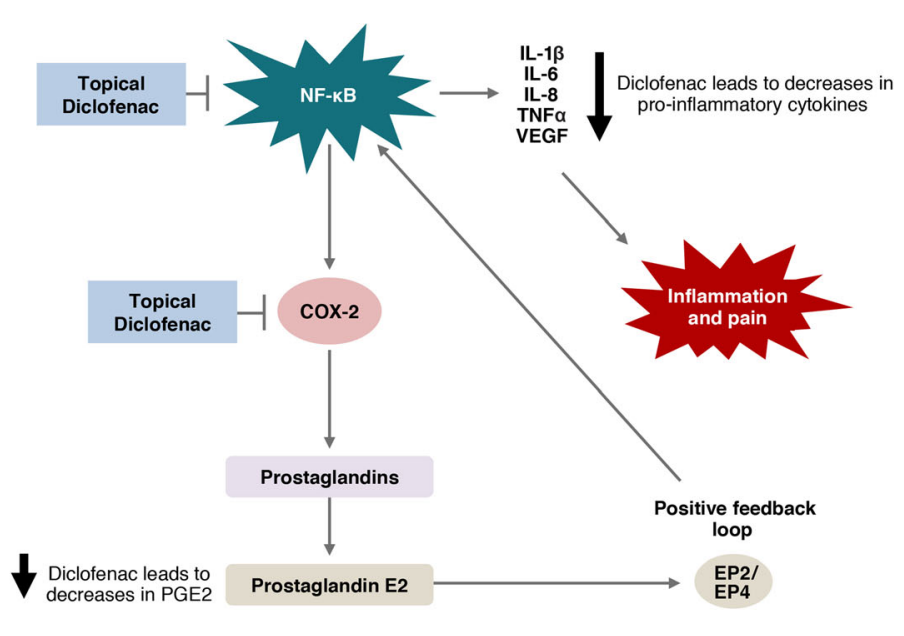

prostanoid receptors for prostaglandin E2; IL-1 $\beta,-6$, and 8 , interleukin-1 $\beta,-6$, and -8 ; NF- $\mathrm{B}$, nuclear factor kappa $\mathrm{B}$; NSAIDs, nonsteroidal anti-inflammatory drugs; TNF $\alpha$, tumor necrosis factor alpha 
effective concentration (MEC) of diclofenac in plasma and target tissue.

For the general efficacy search, we included English-language trials containing outcomes pertaining to pain relief or other measures of improvement associated with use of topical diclofenac or other topical NSAIDs as treatment for OA (at any anatomical site) in adults. The search was conducted using PubMed on October 24, 2018 without date restrictions. A comparable search was subsequently conducted to include safety outcomes of topical diclofenac in patients with OA, and both the efficacy and safety searches were broadened to include systematic reviews, meta-analyses, and professional guidelines on OA.

The search related to onset/duration of action was limited to English-language clinical studies of oral or topical diclofenac in adults with various pain states that reported onset of action (time to start of pain relief, some pain relief, clinically relevant pain relief, or other equivalent outcome) or duration of postdose efficacy. The search was conducted using PubMed on October 10, 2018, without date restrictions. The search results were then narrowed to include only studies of topical diclofenac in OA.

The search on the MEC was conducted broadly to include clinical studies of either oral or topical diclofenac in adults with any painrelated condition that reported plasma/serum or tissue concentrations of diclofenac coupled with an efficacy measure of pain relief or an indirect measure such as reduction of biomarkers, published in English. This search was conducted without date restrictions on October 4, 2018 using PubMed and January 29, 2019 using Embase. The search results were subsequently narrowed to include only studies of topical diclofenac in OA.

For all of the search categories, the authors then added publications based on their knowledge of the field, and additional references were identified by cross-referencing publications. This review article is based on previously conducted studies and does not contain any unpublished original data from studies with human participants or animals performed by any of the authors.

\section{TOPICAL DICLOFENAC EFFICACY IN OSTEOARTHRITIS}

Systematic reviews and meta-analyses have confirmed the efficacy of topical diclofenac in chronic pain due to OA [28-30]. A recent network meta-analysis of randomized controlled trials (RCTs) and observational studies, predominantly of knee OA, reported the superiority of topical diclofenac compared with placebo for pain relief as well as functional improvement [28]. Statistically significant improvements in pain relief were found for diclofenac solution [standardized mean difference (SMD) vs. placebo - 0.29; 95\% confidence interval (CI) $-0.40,-0.18)]$ and diclofenac gel (SMD $-0.30 ; 95 \% \mathrm{CI}-0.39,-0.20)$, with diclofenac patches demonstrating the largest effect on pain relief of any topical NSAID studied (diclofenac, ibuprofen, piroxicam, nimesulide, ketoprofen, salicylate, eltenac, etoricoxib, indomethacin) (SMD - 0.94; 95\% CI - 1.20, - 0.68). Significant improvements in function also were noted for diclofenac solution (SMD - 0.32; 95\% CI $-0.43,-0.21)$, gel (SMD - 0.36; 95\% CI $-0.46,-0.27$ ), and patch (SMD - 0.55; $95 \%$ CI $-0.81,-0.30)$.

Most recently, Wiffen et al. [30] conducted a systematic review of placebo-controlled studies of topical diclofenac in patients with knee or hand OA. In five 6- to 12-week studies, they reported clinical success (defined as $\geq 50 \%$ reduction in pain intensity or Osteoarthritis Research Society International Index response) in $59 \%$ of those treated with topical diclofenac gel or solution vs. $48 \%$ of those treated with placebo [i.e., carrier alone; risk ratio (RR) 1.2; 95\% CI 1.1-1.3). In five 2- to 6-week studies in patients with knee OA, Wiffen et al. reported clinical success $(\geq 50 \%$ reduction in pain or patient global assessment of very good or excellent) in $43 \%$ treated with topical diclofenac plaster, gel, or solution versus $23 \%$ with placebo (RR 1.9; 95\% CI 1.5-2.3).

Three RCTs have directly compared topical diclofenac with an oral NSAID, and all three found them to provide at least equivalent relief of OA pain and other symptoms (Table 1) [31-33]. Two of these trials used oral diclofenac 


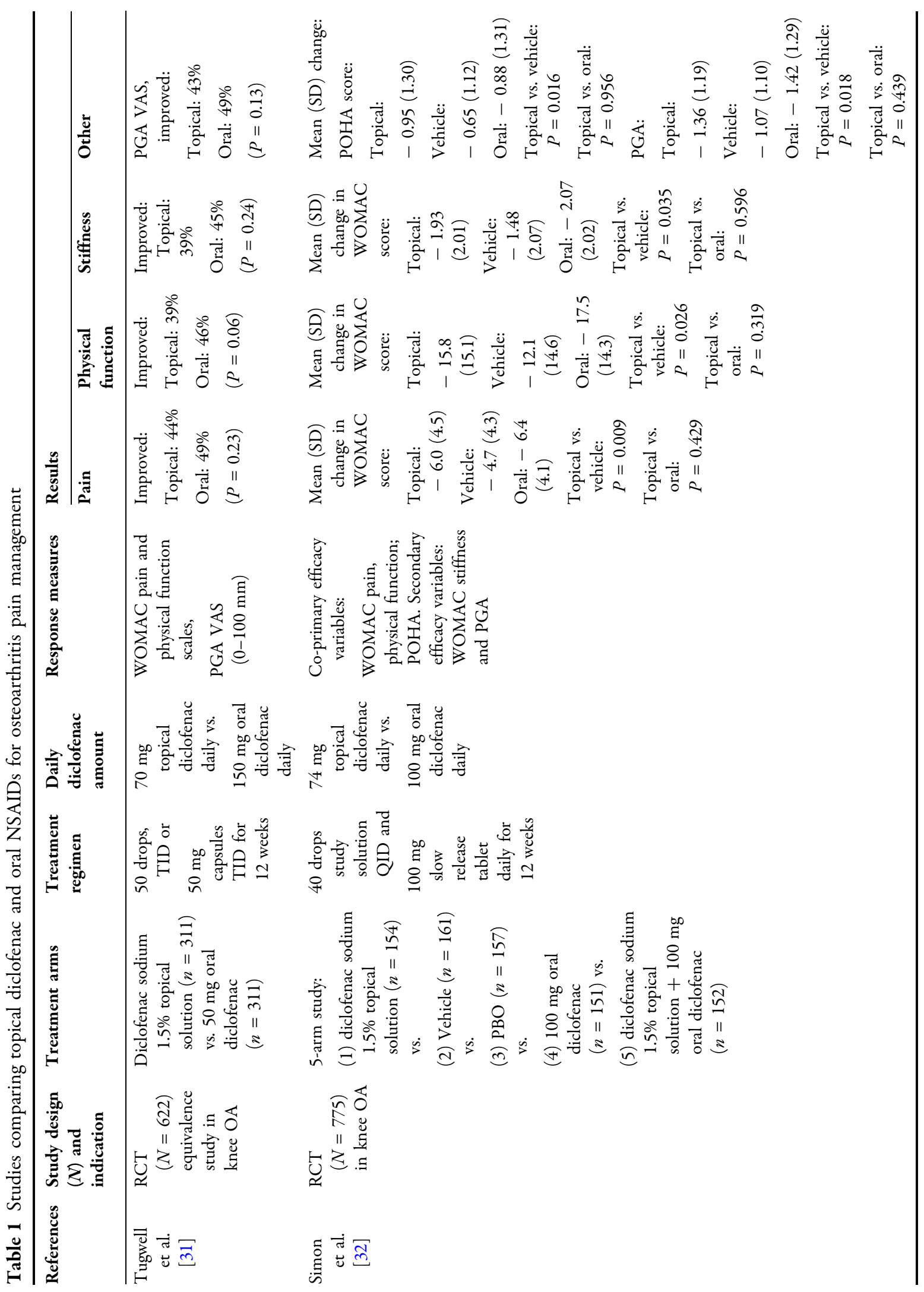




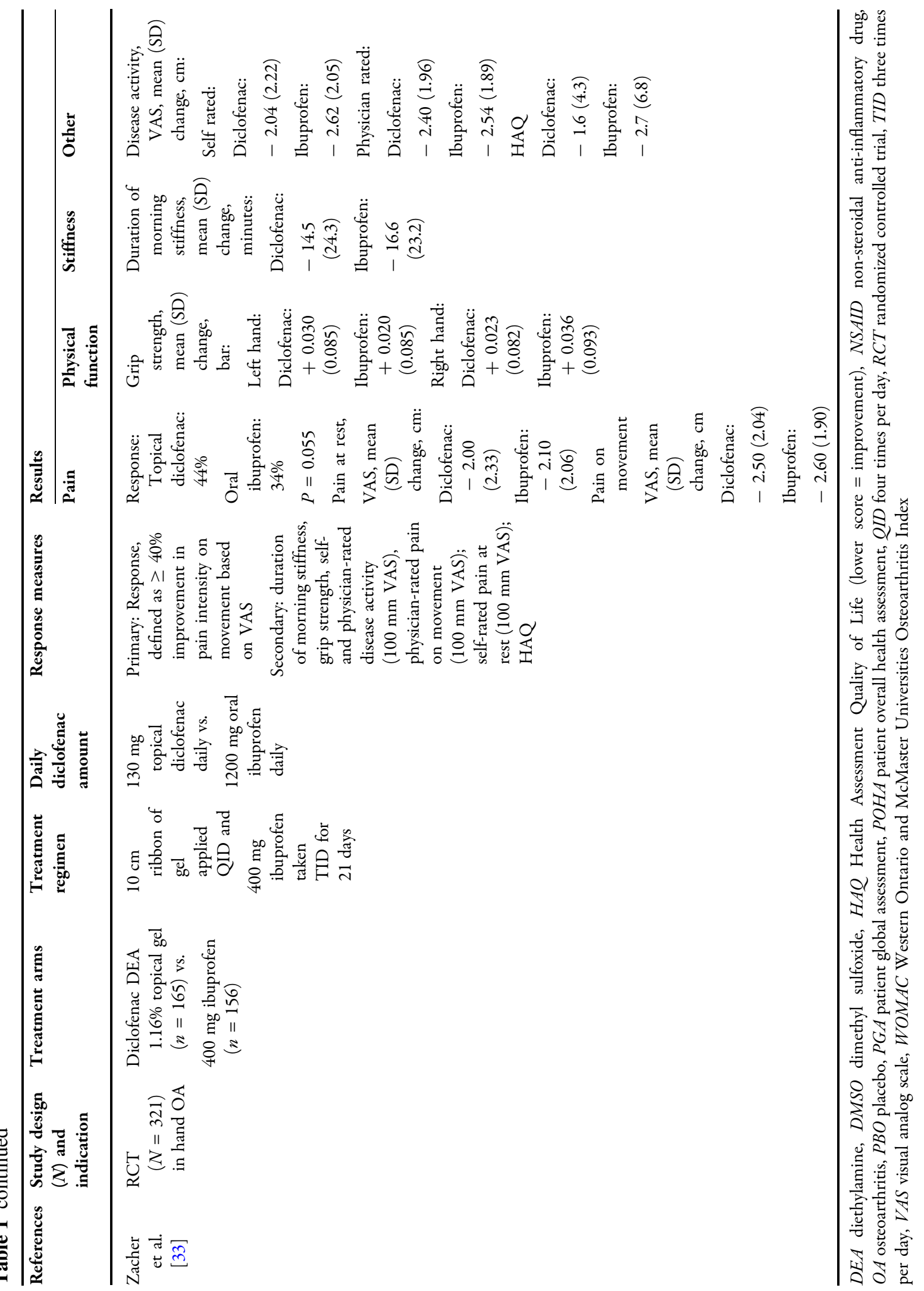


$[31,32]$ as the comparator and the third used ibuprofen [33]. Both of the head-to-head topical vs. oral diclofenac studies were included in the meta-analysis described above [28].

One of the two topical vs. oral diclofenac studies was a 12-week double-blind, doubledummy study comparing topical diclofenac solution $(1.5 \%$ diclofenac sodium in $45.5 \%$ dimethyl sulfoxide [DMSO]) with oral diclofenac capsules $50 \mathrm{mg}$ three times daily (the maximum daily dose) in patients with symptomatic primary knee OA (per protocol $N=492$ ) [31]. Patients with pain in both knees were allowed to apply the topical solution to both, but only the knee with the most pain at baseline was included in the efficacy evaluation. Topical and oral diclofenac were associated with similar rates $(P>0.05)$ of improvement across all variables of pain (44 vs. 49\%), physical function (39 vs. $46 \%$ ), and stiffness ( 39 vs. $45 \%$ ), as well as on a patient global assessment (43 vs. $49 \%$ ), the Western Ontario and McMaster Universities Osteoarthritis Index (WOMAC) at the end of 12-week treatment (or earlier discontinuation). All variables met prespecified criteria for equivalency [31].

A double-blind, double-dummy, 12-week study compared five treatments in 722 patients with knee OA: (1) topical diclofenac solution ( $1.5 \%$ diclofenac sodium in $45.5 \%$ DMSO) plus oral placebo, (2) DMSO solution (45.5\% DMSO without diclofenac) plus oral placebo, (3) topical and oral placebos, (4) oral diclofenac $100 \mathrm{mg}$ slow-release tablets plus placebo solution, and (5) topical diclofenac solution plus oral diclofenac tablets [32]. If both knees were affected by OA, topical treatments were applied only to the knee with more pain at baseline, or to the dominant knee if pain was equivalent in both. Primary efficacy variables were WOMAC pain and physical function and patient overall health assessment (POHA). WOMAC stiffness and patient global assessment (PGA) were secondary outcomes. At the end of treatment, topical diclofenac had efficacy comparable to that of oral diclofenac on all efficacy measures: mean [standard deviation (SD)] change in pain score from baseline to final assessment was - 6.0 (4.5) vs. -6.4 (4.1), $P=0.429$; change in physical function score was -15.8 (15.1) vs.
- 17.5 (14.3), $P=0.319$; change in POHA was $-0.95 \quad(1.30)$ vs. -0.88 (1.31), $P=0.956$; change in stiffness score was - 1.93 (2.01) vs. -2.07 (2.02), $P=0.596$; and change in PGA was -1.36 vs. $-1.42(1.29), P=0.439$. Topical diclofenac was superior $(P<0.05)$ to vehicle solution on all of those outcomes and superior to oral placebo on all outcomes except stiffness. No additional efficacy was evident by combining topical and oral diclofenac [32].

The third head-to-head, randomized, double-blind, double-dummy study compared topical diclofenac diethylamine gel (1.16\%, $10 \mathrm{~cm}$ applied to the affected finger four times daily) with oral ibuprofen (400 mg three times daily, the maximum nonprescription daily dose) for 21 days in 321 patients with OA affecting at least three finger joints (mean, $\sim 8$ ) [33]. Response, defined as $\mathrm{a} \geq 40 \%$ reduction in general pain on movement rated on $100-\mathrm{mm}$ visual analog scale (VAS) at the end of treatment, occurred in $44 \%$ with topical diclofenac and $34 \%$ with ibuprofen and met the predefined criterion for equivalency. Topical diclofenac and oral ibuprofen resulted in comparable improvements with regard to morning stiffness [mean (SD) change -14.5 (24.3) vs. -16.6 (23.2) $\mathrm{min}$ ] and grip strength measured using a dynamometer [left hand: $+0.030(0.085)$ vs. +0.020 (0.085); right hand; +0.023 (0.082) vs. +0.036 (0.093) bar], as well as equivalent improvements on other measures of pain relief, self-rated and physician-rated disease activity, and quality of life [33]. One limitation of all three of these head-to-head studies is that comparisons were reported only at the end of treatment, so whether results were consistent throughout the course of treatment is unknown.

Results of the three studies of topical diclofenac are consistent with findings from studies of other topical NSAIDs (ibuprofen, ketoprofen), which were also found to provide relief from chronic knee pain and stiffness as well as improvements in physical function similar to oral NSAIDs [34-36]. A recent systematic review pooled the three topical diclofenac studies in patients with knee OA [30]. Clinical success (defined as $\geq 50 \%$ reduction in pain, very good or excellent global 
rating, or rating of no or slight pain) was achieved by $55 \%$ of patients with OA treated with topical NSAIDs and 56\% treated with oral NSAIDs (RR 0.98; 95\% CI 0.89-1.08), again supporting the equivalent analgesic effects of topical and oral NSAIDs in OA.

Another recent meta-analysis of RCTs in OA analyzed pain reduction in seven trials of topical NSAIDs (diclofenac or ketoprofen) in knee and hand OA and nine studies of oral NSAIDs (naproxen, ibuprofen, and diclofenac) in knee or hip OA [29]. (One study [32] was also analyzed in the two meta-analyses described above $[28,30])$. For this meta-analysis, authors standardized the WOMAC and VAS pain scores on a 1-100 scale, calculated relative (\%) change from baseline, and then pooled the results taking into account the number of participants in each study arm [29]. Topical NSAIDs were associated with a greater relative reduction in pain (- 40.9\%; 95\% CI 39.4-42.5) than oral NSAIDs (-34.3\%; 95\% CI 32.6-36.0), and this difference was statistically significant $(P<0.001)$. Topical NSAIDs also provided significantly $(P<0.001)$ greater relative reductions in pain (-40.9\%) compared with oral acetaminophen (-32.5\%), COX-2 inhibitors celecoxib and meloxicam (-36.9\%), and opioids tramadol and controlled-release oxycodone (-35.4\%). It should be noted that in this analysis, calculation of relative change from baseline in OA pain intensity was not adjusted for placebo effect [29]. As a point of comparison, the relative change in pain was $-38.1 \%$ with topical placebo and $-31.1 \%$ with oral placebo [29]. Placebo effect, which is typically higher with topical than with oral treatment, may have contributed to the superiority of topical vs. oral NSAIDs in this analysis.

Placebo effect can be considerable and the fact that it is greater with topical than oral administration suggests that the route of administration itself may contribute to perceptions of pain reduction. In one study, WOMAC pain scores were reduced by 38 and $40 \%$ with topical placebos (4.4 and 2.2 g gels, respectively) vs. $29 \%$ with oral placebo [36]. The systematic review described above [30] reported clinical success in $48 \%$ of participants treated with topical placebo in the 6- to 12 -week studies, whereas a separate pooled analysis of seven trials reported that $25 \%$ of participants treated with oral placebo had $\mathrm{a} \geq 50 \%$ reduction in pain after 12 weeks [37]. Patient expectation can enhance drug effects, and the two are not simply additive $[38,39]$. Placebo effects are thought to be influenced by the patient's expectations of or hopes for a treatment effect, treatment setting, patient-provider relationship, beliefs about medications, and contextual/verbal/social cues coupled with prior conditioning [40-42]. They can also be the result of changes related to the natural history of the disease, unrecognized concomitant medication use, regression to the mean, and experimenter and patient biases [42]. With topical therapies, the smell, color, and massage during application also may have psychological effects [43].

Thus, current evidence indicates that topical diclofenac relieves OA pain and stiffness and improves physical function, at least to the same degree as some oral NSAIDs. Notably, two of the three head-to-head studies of topical diclofenac used doses of oral NSAIDs that were lower than maximum prescription doses. However, the results of these two trials were consistent with the trial that used the maximum dose of oral diclofenac as a comparator as well as with studies and meta-analyses that included other topical NSAIDs. It should also be noted that while the studies reviewed here evaluated efficacy in a single target joint, topical diclofenac may be used on multiple joints concurrently by real-world patients with polyarticular arthritis. In such cases, dosing instructions should be carefully followed, particularly with regard to maximum daily doses to be used across all joints. Along with therapeutic effects of the active ingredient, the topical route of administration may positively contribute to the perceived pain reduction in OA.

\section{TOPICAL DICLOFENAC SAFETY AND TOLERABILITY IN OSTEOARTHRITIS}

Adverse events associated with topical diclofenac are primarily local reactions at the application site (dry skin, redness/erythema, pruritus) 
with minimal systemic effects. A meta-analysis of topical NSAIDs found higher rates of overall adverse events (odds ratio [OR] 1.30; 95\% CI 1.10-1.53) with topical diclofenac compared with placebo ( $N=8$ studies) in studies of knee or hand OA, driven predominantly by increased skin and subcutaneous tissue disorders (OR 1.73; 95\% CI 0.96-3.10) [44]. However, there was no increase in gastrointestinal adverse events (OR 1.11; 95\% CI 0.75-1.64) and no increase in severe events (OR 1.19; 95\% CI $0.68-2.07$ ) or serious events (OR 0.94; 95\% CI 0.26-3.42) compared with placebo [44]. Another meta-analysis reported no increase in systemic adverse events (RR 0.89; 95\% CI $0.59-1.3$ ) or gastrointestinal adverse events (RR 1.1; 95\% CI 0.76-1.6) with topical diclofenac compared with carrier alone in knee and hand OA [30]. A randomized, placebo-controlled study found no increase in risk of hepatic enzyme elevations with topical diclofenac solution in a DMSO vehicle compared with the vehicle alone in patients with knee OA [32].

Limited systemic exposure occurs with topical administration (e.g., 6.6\% absorption of applied dose of $1.5 \%$ diclofenac sodium lotion [45]; area under the plasma concentration-time curve from 0 to $24 \mathrm{~h}$ : mean $233 \mathrm{ng} \cdot \mathrm{h} / \mathrm{ml}$ with topical administration of $4 \mathrm{~g}$ diclofenac sodium gel $1 \%$ four times daily vs. $3890 \mathrm{ng} \cdot \mathrm{h} / \mathrm{ml}$ with oral diclofenac sodium $50 \mathrm{mg}$ three times daily for 7 days [46]). This is a potential advantage over oral NSAIDs, which have a higher risk of systemic adverse events.

A pooled analysis of two studies directly comparing the safety of topical diclofenac with that of oral diclofenac in patients with knee OA found that the topical solutions resulted in fewer gastrointestinal events $(25.4$ vs. $39.0 \%$ of patients, $P<0.0001)$, especially dyspepsia $(11.0$ vs. $18.4 \%, P=0.001)$, diarrhea (6.5 vs. $13.4 \%$, $P=0.0004)$, abdominal distension $(6.0$ vs. $10.6 \%, P=0.01)$, and upper abdominal pain (5.6 vs. $12.1 \%, P=0.0005$ ) [47]. Topical diclofenac was also associated with a lower incidence of abnormal liver enzyme levels at the end of the study, including alanine aminotransferase levels (10.4 vs. $22.2 \%, P<0.0001)$, aspartate aminotransferase levels ( 7.0 vs. $14.6 \%$, $P=0.0004)$, and $\gamma$-glutamyl transferase (21.1 vs.
$33.4 \%, P<0.0001)$. Topical administration was associated with more dermatologic reactions (29.0 vs. $6.1 \%, P<0.0001$ ), most commonly dry skin $(24.1$ vs. $1.9 \%, P<0.0001)$, pruritus (4.9 vs. $1.9 \%, P=0.01$ ) and contact dermatitis (4.3 vs. $0.6 \%, P<0.001$ ) at the application site [47]. Similarly, pooling the three trials that directly compared topical diclofenac with oral NSAIDs demonstrated that topical diclofenac was associated with a lower risk of gastrointestinal adverse events (RR 0.63; 95\% CI 0.53-0.73) and a higher risk of local adverse events (RR 8.31; 95\% CI, 4.5-14) than oral NSAIDs [30].

In the pooled analysis of the two studies comparing topical and oral diclofenac, described above, cardiovascular adverse events were numerically, but not statistically significantly, lower with topical than oral diclofenac (1.5 vs. $3.5 \%, P=0.055)$. Oral NSAIDs, especially rofecoxib or diclofenac, have been associated with increased risk of myocardial infarction when used at high doses for prolonged periods [48]. Cardiovascular risk associated with topical vs. oral NSAIDs was also compared in a retrospective cohort study using national claims data from Taiwanese patients with rheumatoid arthritis [49]. Topical nonselective NSAIDs were associated with a lower risk of composite cardiovascular events (myocardial infarction, unstable angina, heart failure, stroke, and revascularization) than oral nonselective NSAIDs (crude incidence 1.83 vs. 2.14 per 100 person-years; HR 0.54 ; $95 \%$ CI $0.37-0.77$ by multivariate Cox model [49]).

Given that topical diclofenac provides at least equivalent analgesia to some oral NSAIDs and has fewer systemic adverse events, topical diclofenac administration may be preferred, especially for older patients with OA and those who have comorbid conditions and/or risk factors for various systemic (gastrointestinal, hepatic, renal, or cardiovascular) adverse events associated with oral NSAIDs. Adverse events are typically local skin reactions, which are usually minor and transient [50]. If required, the products should be discontinued (e.g., by removal of patches or by washing off creams or gels) and application of symptomatic treatments could be considered. 


\section{ONSET OF ACTION IN OSTEOARTHRITIS}

Data on timing of onset of efficacy for topical diclofenac are sparse. Most studies of OA treatment were designed to evaluate efficacy and safety rather than onset of effect. Due to the chronic nature of $\mathrm{OA}$, these studies tend to span a prolonged period of time with emphasis on long-term effects and few assessments capturing short-term effects following treatment application.

Only one study was found that directly assessed onset of action by making hourly assessments during the first few hours after topical diclofenac application. The study was a double-blind RCT of diclofenac epolamine patch containing $180 \mathrm{mg}$ of drug (equivalent to $130 \mathrm{mg}$ of diclofenac) vs. placebo patch in 155 patients with knee OA. Pain intensity was measured using a VAS score hourly for the first $5 \mathrm{~h}$ after patch application [51]. Pain intensity in the diclofenac group was significantly decreased vs. baseline starting at the first assessment, 1-h post treatment (Wilcoxon rank test, $P=0.0316$ ), with further reductions observed over the following hours. Pain relief was significantly greater with diclofenac than placebo beginning at the third hour $(P=0.0034)$. Thus, the authors observed the pain-relieving effect before diclofenac is thought to be detectable in plasma, which, on average, occurs about $4.5 \mathrm{~h}$ after topical application. The authors suggested that during this interval, diclofenac accumulates in the tissue under the patch, permeating the muscles, tendons, and joint capsules in direct contact with the subcutis, thereby explaining this fast onset of local pain relief in the absence of considerable diclofenac concentrations in plasma [51].

Three other studies collected pain ratings daily after topical diclofenac application in patients with OA [52-54], and two collected pain ratings in patients with $\mathrm{OA}$ at 4-7 days $[55,56]$. While none of these studies included time to onset of effect as a specific study outcome, benefit was consistently observed sometime within or at the first week of treatment. Daily (or longer) assessment does not provide a good indication of true time of onset of effect, which could potentially occur before this first measurement.

While the onset of action in chronic conditions may seem less relevant to clinicians than the overall efficacy and safety, for patients, the onset of pain relief likely carries considerable importance. Being able to accurately advise patients as to when they can expect the medication to start working may be important to avoid unjustified treatment cessation, excessive repeat doses, or concomitant intake of oral pain medications while waiting for the topical medication to work. Additional studies to assess the onset of action, in recognition of its importance in pain management, may be useful, not only in the treatment of acute injuries but also in the treatment of chronic conditions like OA.

\section{DURATION OF EFFECT}

Duration of pain relief is an important consideration for analgesic medications, because higher dosing frequency is associated with nonadherence among chronic pain patients [57]. Better adherence to analgesic regimens may reduce suffering and improve physical functioning [58], and the link between treatment adherence/persistence and patient satisfaction has been well established across a spectrum of diseases including chronic pain states [59].

One large $(N=260)$ double-blind, vehiclecontrolled study of $2 \%$ diclofenac sodium topical solution applied twice daily in adults with knee OA found that analgesia as determined by WOMAC pain score was maintained throughout the 12-h dosing interval among responders [53]. In two (selected) responder groups $[\geq 30 \%$ and $\geq 50 \%$ reduction in numeric rating scale (NRS) score at week 4 vs. baseline], scores on an 11-point NRS during active treatment were not significantly different at midday vs. evening, suggesting that the twice-daily regimen maintained pain relief in these responder groups throughout the 12-h dosing interval at week 4 [53]. This long-lasting effect may be attributed to the slower clearance of diclofenac from the inflamed tissue 
compared with plasma [60-62], as discussed in the next section of this review.

Further studies investigating the duration of analgesia with other topical diclofenac formulations may be informative.

\section{PHARMACOKINETIC EFFECT COMPARTMENTS AND MINIMUM EFFECTIVE CONCENTRATION}

\section{Plasma and Synovial Tissue Concentrations After Topical Administration}

It is well established that topical diclofenac penetrates the skin, permeates underlying tissues, and enters the synovium (Fig. 2) [63-66]. Analgesic efficacy may be dependent on diclofenac concentration in the synovial compartment, the site of diclofenac's activity. However, reports of the relative distribution of diclofenac following topical administration in joint tissue (the "effect compartment") and in plasma (a "side effect compartment") are variable [65-68], and the minimum concentration needed in plasma or synovial tissue to achieve a meaningful reduction in pain intensity is still poorly defined.

The pharmacokinetic profile of diclofenac in the synovium differs from that in the plasma, with a faster rate of elimination in plasma [60-62]. Following oral administration, diclofenac has been found to persist in inflamed tissues for up to $12 \mathrm{~h}$ after dosing, potentially accounting for its extended duration of action compared with its short plasma half-life of $1-2 \mathrm{~h}[60,62,69]$.

There are certain reasons for diclofenac to preferentially accumulate in the inflamed joint

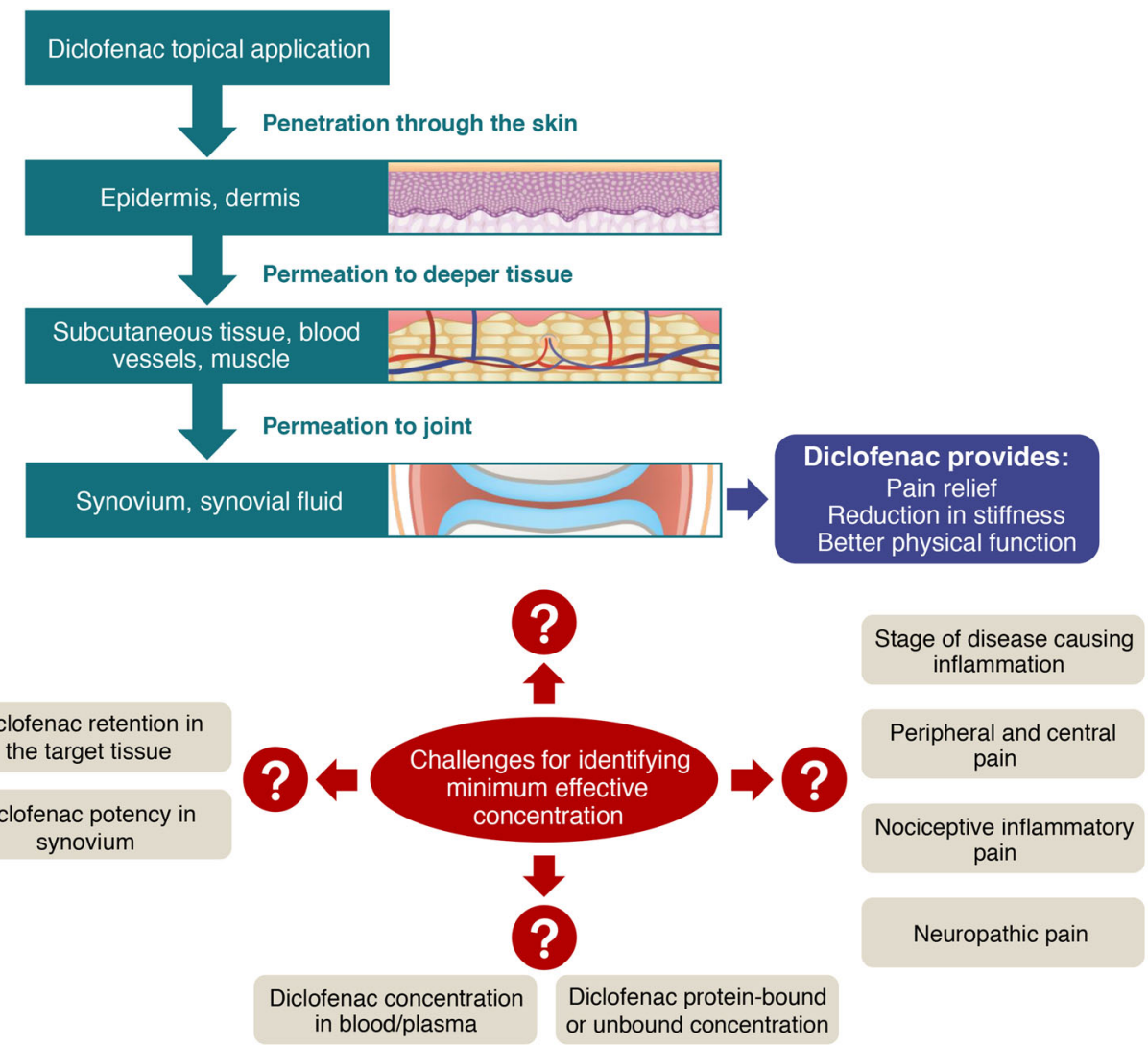

Fig. 2 Flow of diclofenac from topical application to the joint capsule showing known steps (green arrows) and potential influencers of minimum effective concentration (red question marks) 
tissues. Drugs that are highly protein-bound [e.g., diclofenac (>99\% in plasma [70])] concentrate wherever albumin concentrates [63]. Albumin concentrations are increased in inflamed synovial tissue and fluid compared with the joints of healthy persons [9, 71]. Diclofenac's protein-binding and short plasma half-life (1-2 h) creates a high plasma/tissue gradient promoting movement into inflamed joints $[67,72,73]$. Diclofenac has hydrophilic/ lipophilic polarity, which also facilitates permeation of and retention in the intracellular spaces and cell membranes in inflamed tissues $[17,67,72-74]$. Given the lack of a clear association between diclofenac levels in plasma compared with target tissues, attainment of a specific plasma concentration may be unrelated to therapeutic effect.

The results of a randomized, double-blind, placebo-controlled crossover study suggest that analgesic efficacy may be dependent on diclofenac concentration in the synovial compartment, the site of diclofenac's activity. This study compared the analgesic efficacy of topical (65 $\mathrm{mg}$ ) and oral (93 mg) diclofenac acid and placebo in reducing inflammatory hyperalgesia from a "freeze lesion" in ten healthy volunteers [75]. That study found that topical diclofenac was more effective than oral diclofenac $1 \mathrm{~h}$ after dosing (though not at later assessments) and that this efficacy coincided with higher tissue concentrations in the group that received topical administration $(46.1 \pm 25.8 \mathrm{ng} / \mathrm{ml}$ vs. $11.4 \pm 2.09 \mathrm{ng} / \mathrm{ml}$, $P<0.02)$ at about $1-1.5 \mathrm{~h}$, when no diclofenac was detectable in plasma after topical administration [75]. No dose-response relationship has been reported for synovial diclofenac concentrations and analgesic efficacy. Data are still lacking on the minimum amount of diclofenac needed in the joint to achieve pain relief.

In summary, diclofenac concentrations in inflamed joint tissue may be more relevant to potential therapeutic effect than plasma concentrations. Diclofenac penetrates these "effect compartments" at the site of inflammation and drug activity. Diclofenac is known to be effective in reducing pain in these target joints; however, a specific MEC in synovial tissue or synovial fluid has not been defined.

\section{Identifying the MEC Based on Prostaglandin E2 (PGE2) Inhibition and Inflammatory Mediators}

Because the mechanism of NSAIDs indirectly involves reduction of PGE2 via inhibition of COX-2 enzymes, PGE2 serves as a surrogate marker of COX-2 inhibition. Diclofenac is an effective inhibitor of PGE2 production and has been reported to be 3-1000 times more potent on a molar basis compared with other NSAIDs in its ability to inhibit COX activity [76, 77]. Therefore, compared with other NSAIDs, much smaller diclofenac concentrations may be required to achieve the same level of PGE2 reduction and therapeutic effect.

Some investigators have demonstrated relationships between synovial NSAID concentrations and PGE2 reduction. Chlud and Wagner previously suggested that a diclofenac concentration of $100-500 \mathrm{ng} / \mathrm{ml}$ in the synovium was consistent with clinical efficacy and in agreement with in vitro studies correlating these concentrations with inhibition of prostaglandin synthesis [43]. We have previously estimated that a synovial diclofenac concentration of $45 \mathrm{ng} / \mathrm{ml}$ would result in a $50 \%$ reduction $\left(\mathrm{IC}_{50}\right)$ in PGE2 [63]. In another study, Liauw et al. [78] found that after a single oral 75-mg dose of diclofenac, diclofenac concentrations in synovial fluid peaked at hour $4(181 \mathrm{ng} / \mathrm{ml})$, coinciding with a 95\% reduction in PGE2 levels in synovial fluid. Diclofenac concentrations gradually decreased to $60 \mathrm{ng} / \mathrm{ml}$ at hour 12 , and PGE2 inhibition remained at about 50\% during that interval. After twice-daily dosing for a week, on day 8 the diclofenac concentration in synovial fluid again peaked at hour $4(227 \mathrm{ng} /$ $\mathrm{ml}$ ) and declined to $117 \mathrm{ng} / \mathrm{ml}$ at hour 12 , while PGE2 levels remained suppressed throughout the 12-h dosing interval. Martel-Pelletier et al. [79] measured PGE2 in ex vivo synovial membrane and cartilage tissue samples from eight patients with $\mathrm{OA}$ after addition of diclofenac 125 and $250 \mathrm{ng} / \mathrm{ml}$; this resulted in $>90 \%$ inhibition of PGE2 synthesis. However, the relationship between PGE2 reduction and analgesic effect remains poorly elucidated.

After exposure to NSAIDs, inflammatory cytokines that follow PGE2 in the signal 
transduction pathway [e.g., interleukin-6 (IL-6) and tumor necrosis factor alpha $(\mathrm{TNF} \alpha)]$ are reduced along with PGE2 [20, 26, 63, 80] (Fig. 1 [19-26]). Clinical data measuring inflammatory biomarkers after topical diclofenac use are limited. A randomized, open-label study of oral NSAIDs, including slow-release diclofenac $75 \mathrm{mg}$ once or twice daily, ibuprofen $600 \mathrm{mg}$ two or three times daily, or celecoxib $200 \mathrm{mg}$ once or twice daily, in patients with OA reported dose-dependent reductions in IL-6, TNF $\alpha$, and vascular endothelial growth factor in the synovial fluid, which significantly correlated with improvement in total WOMAC scores [25]. As a point of reference, an oral 75-mg dose is associated with an estimated synovium diclofenac concentration of $50-175 \mathrm{ng} / \mathrm{ml}$ [63]. There is also evidence that NSAIDs may reduce proinflammatory cytokines like IL-6 at the transcription level through effects on the transcription factor NF- $\mathrm{kB}$ (nuclear factor kappa B) and independent of effects on prostaglandins [26].

Whereas the severity of OA-related pain does not correlate with the degree of structural joint damage $[81,82]$, the presence of synovitis or effusion has been found to predict joint pain in OA $[4,6,83,84]$. Furthermore, the presence of pro-inflammatory biomarkers in synovial fluid has been found to correlate with pain, and different inflammatory mediators are associated with different pain manifestations (Table 2) [85-88]. Leung et al. [85] estimated that a change in inflammatory biomarkers (e.g., TNF $\alpha$, IL-6, IL-8) of two standard deviations might be associated with meaningful pain response; however, it remains unknown what concentration of diclofenac would be needed to produce such a change in these biomarkers.

In summary, existing evidence based largely on studies of oral administration suggest that a diclofenac concentration of $45 \mathrm{ng} / \mathrm{ml}$ in synovial tissue is associated with a $50 \%$ reduction in PGE2, while concentrations $>100 \mathrm{ng} / \mathrm{ml}$ are associated with $>80 \%$ reduction in PGE2. Further research is needed before it can be determined whether these concentrations also apply to topical diclofenac and to clarify what degree of reduction in COX-2, PGE2, and downstream inflammatory cytokines is required for clinically meaningful pain relief.

Table 2 Cytokines associated with pain, and direct effects on sensory neurons and other downstream inflammatory mediators

\begin{tabular}{|c|c|c|c|c|c|c|}
\hline Cytokine & $\begin{array}{l}\text { Pain at } \\
\text { rest }\end{array}$ & $\begin{array}{l}\text { Pain on } \\
\text { movement }\end{array}$ & $\begin{array}{l}\text { Total } \\
\text { WOMAC }\end{array}$ & $\begin{array}{l}\text { Mechanical } \\
\text { hypersensitivity }\end{array}$ & $\begin{array}{l}\text { Direct effects on } \\
\text { sensory neurons }\end{array}$ & $\begin{array}{l}\text { Downstream effects on } \\
\text { other inflammatory } \\
\text { mediators }\end{array}$ \\
\hline $\mathrm{TNF} \alpha$ & $\begin{array}{c}(+) \text { Leung } \\
{[85]}\end{array}$ & $\begin{array}{l}(+) \text { Leung } \\
{[85]}\end{array}$ & $\begin{array}{c}(+) \text { Gallelli } \\
{[25]}\end{array}$ & $\begin{array}{l}(+) \text { Richter } \\
{[86]} \\
\quad \text { (preclinical) }\end{array}$ & $\begin{array}{l}(+) \text { Richter }[86] \\
\text { (preclinical) and } \\
\text { Miller [88] } \\
\text { (review) }\end{array}$ & $\begin{array}{l}(+) \text { Miller [88] } \\
\quad(\text { review })\end{array}$ \\
\hline IL-6 & $\begin{array}{l}\text { NA; Leung } \\
\quad[85]\end{array}$ & $\begin{array}{l}(+) \text { Leung } \\
{[85]}\end{array}$ & $\begin{array}{l}(+) \text { Gallelli } \\
{[25]}\end{array}$ & $\begin{array}{l}(+) \text { Brenn }[87] \\
\text { (preclinical) }\end{array}$ & $\mathrm{NE}$ & NE \\
\hline IL-8 & $\begin{array}{l}\text { NA; Leung } \\
\text { [85] }\end{array}$ & $\begin{array}{c}(+) \text { Leung } \\
{[85]}\end{array}$ & $\mathrm{NE}$ & $\mathrm{NE}$ & $\mathrm{NE}$ & $\mathrm{NE}$ \\
\hline IL- $1 \beta$ & $\mathrm{NE}$ & $(-)$ Leung [85] & $\mathrm{NE}$ & $\mathrm{NE}$ & $\begin{array}{l}(+) \text { Miller [88] } \\
\text { (review) }\end{array}$ & $\begin{array}{l}(+) \text { Miller [88] } \\
(\text { review })\end{array}$ \\
\hline VEGF & $\mathrm{NE}$ & $\mathrm{NE}$ & $\begin{array}{l}(+) \text { Gallelli } \\
{[25]}\end{array}$ & $\mathrm{NE}$ & $\mathrm{NE}$ & $\mathrm{NE}$ \\
\hline
\end{tabular}

(+) positive association, (-) negative (inverse) association, $I L$ interleukin, $N A$ no association identified, $N E$ not evaluated in the articles identified, $T N F \alpha$ tumor necrosis factor alpha, $V E G F$ vascular endothelial growth factor 


\section{Challenges in Identifying the MEC}

Patient- and disease-related factors can lead to variability in individual responses to topical diclofenac, which poses a challenge to identification of an MEC. Such factors include the stage of OA progression, the variable extent and nature of inflammation, and the underlying mechanisms of the patient's pain (inflammatory, nociceptive, and/or central; Fig. 2 $[20,21,63])$.

Pain phenotypes differ at different stages of OA. Patients with early OA tend to experience predictable bouts of pain triggered by activity. At its middle stages, OA is associated with more constant background pain/achiness, especially at night, and in advanced $\mathrm{OA}$, patients may experience constant background pain accompanied by intermittent bouts of unpredictable severe pain $[5,89]$. Some patients with OA progress rapidly through these stages whereas others may have more stable disease. The extent of inflammation varies over the course of the disease, with more inflammatory mediators (e.g., TNF $\alpha$, IL-1 $\beta$ ) present in early ( $<1$ year) knee OA compared with advancedstage knee OA [5, 85].

While bone remodeling, loss of cartilage, and narrowing of the joint space are the characteristic morphological changes observed in OA, pain often is associated with the presence of inflammation (synovitis) [4, 6, 84]. In such cases, peripheral nerves in the various degenerating joint tissues become exposed to the intraarticular environment rich in cytokines, chemokines, proteases, prostaglandins, and neuropeptides, which serve as ligands for nociceptors [86, 90-92]. Ligand binding lowers the threshold of these receptors and sensitizes the peripheral neurons, such that even normal joint movement triggers a pain response [86, 87, 93]. In addition, based on murine models, serine proteases (e.g., mast cell tryptase and neutrophil elastase) may activate protease-activated receptor-2, thereby serving as signaling molecules for leukocyte trafficking and nociceptive OA joint pain $[94,95]$.

In addition to nociceptive pain, neuropathic pain may result from direct damage to the nerves in the injured joint, dorsal root ganglia, and spinal cord $[11,96,97]$. Neuropathic pain is not responsive to NSAIDs [92].

Central sensitization can be another major component of OA pain, manifesting as increased sensitivity to noxious stimuli (hyperalgesia) or interpretation of non-noxious stimuli as painful (allodynia) [27, 92]. Although there is some evidence that diclofenac crosses the blood-brain barrier [98, 99], low concentrations are likely to enter the central nervous system following topical administration given the limited systemic exposure associated with topical use. Therefore, the neuropathic component of OA pain is not expected to be responsive to topical NSAIDs.

Thus, OA pain may have peripheral elements (e.g., inflammation, sensitization of peripheral neurons, direct damage to nerves) as well as central components (e.g., hyperalgesia and allodynia), and these heterogeneous underlying mechanisms may respond differently to treatment $[5,92,100]$. Patients with earlier-stage OA pain related to active inflammation, particularly inflammatory mediators downstream of PGE2, would likely have the best response to topical NSAIDs based on their mechanism of action, but this remains to be confirmed. Given that the magnitude of inflammation, the specific inflammatory mediators present, and the extent to which central pain mechanisms contribute may vary from patient to patient and over the course of $\mathrm{OA}$, it is not surprising that the existing, albeit limited, data related to concentrations achieved in different target areas have been variable/inconsistent, and it may not be possible to identify a single diclofenac MEC that would universally apply to all patients with OA.

\section{CONCLUSIONS}

The use of topical NSAIDs including diclofenac is endorsed by a majority of treatment guidelines for management of OA-related joint pain. In multiple head-to-head RCTs, topical diclofenac provided pain relief, improvement of physical function, and reduction in stiffness comparable to that of some oral NSAIDs, with fewer systemic side effects, in patients with knee or hand OA. The topical route of administration may 
further enhance and benefit the analgesic effects, given that topical placebo is more effective than oral placebo. Limited data suggest that pain relief begins within a few hours of topical administration and is generally well sustained throughout the 12-h dosing interval, especially with ongoing use.

Following topical administration, diclofenac accumulates in inflamed joint tissue; however, no specific diclofenac MECs have been identified. While synovial tissue concentrations are likely to be more relevant than plasma concentrations, and have been found to correlate with PGE2 reductions (a measure of COX-2 inhibition), identification of a specific synovial MEC is hampered by the fact that OA is a heterogeneous disease with widely varying pain mechanisms in individual patients and at different stages of the disease. The concentration of different biomarkers varies over the course of $\mathrm{OA}$ and the reduction of specific biomarkers seems to impact different aspects of pain sensations.

While efficacy of topical diclofenac in OA is well established, further research is needed to better elucidate what degree of reduction in PGE2 or other downstream inflammatory mediators (e.g., IL-6, TNF $\alpha$ ) in synovial tissue is necessary to achieve an analgesic effect. Additional research also is needed to more clearly identify time to onset of action and duration of pain relief to differentiate individual topical formulations of diclofenac.

\section{ACKNOWLEDGEMENTS}

Funding. This review and the Rapid Service Fee were funded by GSK Consumer Healthcare S.A., Nyon, Switzerland.

Medical Writing Assistance. Medical writing assistance was provided to the authors by Lauren Cerruto of Peloton Advantage, LLC, an OPEN Health company, Parsippany, NJ, and funded by GSK Consumer Healthcare S.A., Nyon, Switzerland.
Authorship. All named authors meet the International Committee of Medical Journal Editors (ICMJE) criteria for authorship for this article, take responsibility for the integrity of the work as a whole, and have given their approval for this version to be published.

Disclosures. Frédérique Bariguian Revel, Marina Fayet and Martina Hagen are employees of GSK Consumer Healthcare S.A., Nyon, Switzerland, which produces a wide range of analgesics (e.g., paracetamol, ibuprofen, diclofenac), including both topical and oral formulations.

Compliance with Ethics Guidelines. This review article is based on previously conducted studies and does not contain any unpublished original data from studies with human participants or animals performed by any of the authors.

Open Access. This article is licensed under a Creative Commons Attribution-NonCommercial 4.0 International License, which permits any non-commercial use, sharing, adaptation, distribution and reproduction in any medium or format, as long as you give appropriate credit to the original author(s) and the source, provide a link to the Creative Commons licence, and indicate if changes were made. The images or other third party material in this article are included in the article's Creative Commons licence, unless indicated otherwise in a credit line to the material. If material is not included in the article's Creative Commons licence and your intended use is not permitted by statutory regulation or exceeds the permitted use, you will need to obtain permission directly from the copyright holder. To view a copy of this licence, visit http://creativecommons.org/licenses/by$\mathrm{nc} / 4.0 /$.

\section{REFERENCES}

1. GBD 2017 Collaborators. Global, regional, and national incidence, prevalence, and years lived with disability for 354 diseases and injuries for 195 countries and territories, 1990-2017: a systematic 
analysis for the Global Burden of Disease Study 2017. Lancet. 2018;392(10159):1789-858.

2. Vina ER, Kwoh CK. Epidemiology of osteoarthritis: literature update. Curr Opin Rheumatol. 2018;30(2):160-7.

3. Hunter DJ, Bierma-Zeinstra S. Osteoarthritis. Lancet. 2019;393(10182):1745-59.

4. Lo GH, McAlindon TE, Niu J, Zhang Y, Beals C, Dabrowski C, et al. Bone marrow lesions and joint effusion are strongly and independently associated with weight-bearing pain in knee osteoarthritis: data from the osteoarthritis initiative. Osteoarthr Cartil. 2009;17(12):1562-9.

5. Hawker GA, Stewart L, French MR, Cibere J, Jordan JM, March L, et al. Understanding the pain experience in hip and knee osteoarthritis-an OARSI/ OMERACT initiative. Osteoarthr Cartil. 2008;16(4): 415-22.

6. Kornaat PR, Bloem JL, Ceulemans RY, Riyazi N, Rosendaal FR, Nelissen RG, et al. Osteoarthritis of the knee: association between clinical features and MR imaging findings. Radiology. 2006;239(3): 811-7.

7. Deveza LA, Loeser RF. Is osteoarthritis one disease or a collection of many? Rheumatology (Oxford). 2018;57(suppl_4):34-42.

8. Tan AL, Toumi H, Benjamin M, Grainger AJ, Tanner SF, Emery P, et al. Combined high-resolution magnetic resonance imaging and histological examination to explore the role of ligaments and tendons in the phenotypic expression of early hand osteoarthritis. Ann Rheum Dis. 2006;65(10): 1267-72.

9. Sohn DH, Sokolove J, Sharpe O, Erhart JC, Chandra $\mathrm{PE}$, Lahey LJ, et al. Plasma proteins present in osteoarthritic synovial fluid can stimulate cytokine production via Toll-like receptor 4. Arthritis Res Ther. 2012;14(1):R7.

10. Sokolove J, Lepus CM. Role of inflammation in the pathogenesis of osteoarthritis: latest findings and interpretations. Ther Adv Musculoskelet Dis. 2013;5(2):77-94.

11. Orita S, Ishikawa T, Miyagi M, Ochiai N, Inoue G, Eguchi $Y$, et al. Pain-related sensory innervation in monoiodoacetate-induced osteoarthritis in rat knees that gradually develops neuronal injury in addition to inflammatory pain. BMC Musculoskelet Disord. 2011;12:134.

12. Gosset M, Berenbaum F, Levy A, Pigenet A, Thirion S, Saffar JL, et al. Prostaglandin E2 synthesis in cartilage explants under compression: mPGES-1 is a mechanosensitive gene. Arthritis Res Ther. 2006;8(4):R135.

13. Pulai JI, Chen H, Im HJ, Kumar S, Hanning C, Hegde PS, et al. NF-kappa B mediates the stimulation of cytokine and chemokine expression by human articular chondrocytes in response to fibronectin fragments. J Immunol. 2005;174(9):5781-8.

14. Wright EA, Katz JN, Cisternas MG, Kessler CL, Wagenseller A, Losina E. Impact of knee osteoarthritis on health care resource utilization in a US population-based national sample. Med Care. 2010;48(9):785-91.

15. Menon J, Mishra P. Health care resource use, health care expenditures and absenteeism costs associated with osteoarthritis in US healthcare system. Osteoarthr Cartil. 2018;26(4):480-4.

16. Kolasinski SL, Neogi T, Hochberg MC, Oatis C, Guyatt G, Block J, et al. 2019 American College of Rheumatology/Arthritis Foundation Guideline for the management of osteoarthritis of the hand, hip, and knee. Arthritis Care Res (Hoboken). 2020;72(2): 149-62.

17. Singh P, Roberts MS. Skin permeability and local tissue concentrations of nonsteroidal anti-inflammatory drugs after topical application. J Pharmacol Exp Ther. 1994;268(1):144-51.

18. Patrono C, Patrignani P, Garcia Rodriguez LA. Cyclooxygenase-selective inhibition of prostanoid formation: transducing biochemical selectivity into clinical read-outs. J Clin Invest. 2001;108(1):7-13.

19. Ricciotti E, FitzGerald GA. Prostaglandins and inflammation. Arterioscler Thromb Vasc Biol. 2011;31(5):986-1000.

20. van Erk MJ, Wopereis S, Rubingh $C$, van Vliet $T$, Verheij $\mathrm{E}$, Cnubben $\mathrm{NH}$, et al. Insight in modulation of inflammation in response to diclofenac intervention: a human intervention study. BMC Med Genom. 2010;3:5.

21. Liu T, Zhang L, Joo D, Sun SC. NF-kappaB signaling in inflammation. Signal Transduct Target Ther. 2017;2:17023.

22. Gan TJ. Diclofenac: an update on its mechanism of action and safety profile. Curr Med Res Opin. 2010;26(7):1715-31.

23. Aoki T, Narumiya S. Prostaglandins and chronic inflammation. Trends Pharmacol Sci. 2012;33(6): 304-11.

24. Sreeramkumar V, Fresno M, Cuesta N. Prostaglandin E2 and T cells: friends or foes? Immunol Cell Biol. 2012;90(6):579-86. 
25. Gallelli L, Galasso O, Falcone D, Southworth S, Greco M, Ventura V, et al. The effects of nonsteroidal anti-inflammatory drugs on clinical outcomes, synovial fluid cytokine concentration and signal transduction pathways in knee osteoarthritis. A randomized open label trial. Osteoarthr Cartil. 2013;21(9):1400-8.

26. Mahdy AM, Galley HF, Abdel-Wahed MA, el-Korny KF, Sheta SA, Webster NR. Differential modulation of interleukin- 6 and interleukin- 10 by diclofenac in patients undergoing major surgery. Br J Anaesth. 2002;88(6):797-802.

27. Minami T, Nakano H, Kobayashi T, Sugimoto Y, Ushikubi F, Ichikawa A, et al. Characterization of EP receptor subtypes responsible for prostaglandin E2induced pain responses by use of EP1 and EP3 receptor knockout mice. $\mathrm{Br} \mathrm{J}$ Pharmacol. 2001;133(3):438-44.

28. Zeng C, Wei J, Persson MSM, Sarmanova A, Doherty $\mathrm{M}$, Xie D, et al. Relative efficacy and safety of topical non-steroidal anti-inflammatory drugs for osteoarthritis: a systematic review and network meta-analysis of randomised controlled trials and observational studies. Br J Sports Med. 2018;52(10): $642-50$.

29. Stewart M, Cibere J, Sayre EC, Kopec JA. Efficacy of commonly prescribed analgesics in the management of osteoarthritis: a systematic review and meta-analysis. Rheumatol Int. 2018;38(11): 1985-97.

30. Wiffen PJ, Xia J. Systematic review of topical diclofenac for the treatment of acute and chronic musculoskeletal pain. Curr Med Res Opin. 2020. https://doi.org/10.6084/m9.figshare.11628036.v1.

31. Tugwell PS, Wells GA, Shainhouse JZ. Equivalence study of a topical diclofenac solution (pennsaid) compared with oral diclofenac in symptomatic treatment of osteoarthritis of the knee: a randomized controlled trial. J Rheumatol. 2004;31(10): 2002-12.

32. Simon LS, Grierson LM, Naseer Z, Bookman AA, Zev SJ. Efficacy and safety of topical diclofenac containing dimethyl sulfoxide (DMSO) compared with those of topical placebo, DMSO vehicle and oral diclofenac for knee osteoarthritis. Pain. 2009;143(3):238-45.

33. Zacher J, Burger KJ, Farber L, Grave M, Abberger H, Bertsch K. Topical diclofenac emulgel versus oral ibuprofen in the treatment of active osteoarthritis of the finger joints (Heberden's and/or Bouchard's nodes): a double-blind, controlled, randomized study. Postgrad Med. 2011;123(5):1-7.
34. Underwood M, Ashby D, Cross P, Hennessy E, Letley L, Martin J, et al. Advice to use topical or oral ibuprofen for chronic knee pain in older people: randomised controlled trial and patient preference study. BMJ. 2008;336(7636):138-42.

35. Tiso RL, Tong-Ngork S, Fredlund KL. Oral versus topical ibuprofen for chronic knee pain: a prospective randomized pilot study. Pain Physician. 2010;13(5):457-67.

36. Conaghan PG, Dickson J, Bolten W, Cevc G, Rother M. A multicentre, randomized, placebo- and activecontrolled trial comparing the efficacy and safety of topical ketoprofen in Transfersome gel (IDEA-033) with ketoprofen-free vehicle (TDT 064) and oral celecoxib for knee pain associated with osteoarthritis. Rheumatology (Oxford). 2013;52(7): 1303-12.

37. Moore RA, Moore OA, Derry S, Peloso PM, Gammaitoni AR, Wang H. Responder analysis for pain relief and numbers needed to treat in a meta-analysis of etoricoxib osteoarthritis trials: bridging a gap between clinical trials and clinical practice. Ann Rheum Dis. 2010;69(2):374-9.

38. Schenk LA, Sprenger C, Geuter S, Buchel C. Expectation requires treatment to boost pain relief: an fMRI study. Pain. 2014;155(1):150-7.

39. Colloca L, Lopiano L, Lanotte M, Benedetti F. Overt versus covert treatment for pain, anxiety, and Parkinson's disease. Lancet Neurol. 2004;3(11): 679-84.

40. Dodd S, Dean OM, Vian J, Berk M. A review of the theoretical and biological understanding of the nocebo and placebo phenomena. Clin Ther. 2017;39(3):469-76.

41. Colagiuri B, Schenk LA, Kessler MD, Dorsey SG, Colloca L. The placebo effect: from concepts to genes. Neuroscience. 2015;307:171-90.

42. Benedetti F. Placebo and the new physiology of the doctor-patient relationship. Physiol Rev. 2013;93(3):1207-46.

43. Chlud K, Wagener HH. Percutaneous non-steroidal anti-inflammatory drug (NSAID) therapy with particular reference to pharmacokinetic factors. EULAR Bull. 1987;2:40-3.

44. Honvo G, Leclercq V, Geerinck A, Thomas T, Veronese N, Charles A, et al. Safety of topical nonsteroidal anti-inflammatory drugs in osteoarthritis: outcomes of a systematic review and meta-analysis. Drugs Aging. 2019;36(Suppl 1):45-64.

45. Hui X, Hewitt PG, Poblete N, Maibach HI, Shainhouse JZ, Wester RC. In vivo bioavailability and 
metabolism of topical diclofenac lotion in human volunteers. Pharm Res. 1998;15(10):1589-95.

46. Kienzler JL, Gold M, Nollevaux F. Systemic bioavailability of topical diclofenac sodium gel $1 \%$ versus oral diclofenac sodium in healthy volunteers. J Clin Pharmacol. 2010;50(1):50-61.

47. Roth SH, Fuller P. Diclofenac topical solution compared with oral diclofenac: a pooled safety analysis. J Pain Res. 2011;4:159-67.

48. Moore N. Coronary risks associated with diclofenac and other NSAIDs: an update. Drug Saf. 2020. https://doi.org/10.1007/s40264-019-00900-8.

49. Lin TC, Solomon DH, Tedeschi SK, Yoshida K, Kao Yang YH. Comparative risk of cardiovascular outcomes between topical and oral nonselective NSAIDs in Taiwanese patients with rheumatoid arthritis. J Am Heart Assoc. 2017;6(11):e006874.

50. Bannuru RR, Osani MC, Vaysbrot EE, Arden NK, Bennell K, Bierma-Zeinstra SMA, et al. OARSI guidelines for the non-surgical management of knee, hip, and polyarticular osteoarthritis. Osteoarthr Cartil. 2019;27(11):1578-89.

51. Petersen B, Rovati S. Diclofenac epolamine (Flector) patch: evidence for topical activity. Clin Drug Investig. 2009;29(1):1-9.

52. Niethard FU, Gold MS, Solomon GS, Liu JM, Unkauf $\mathrm{M}$, Albrecht $\mathrm{HH}$, et al. Efficacy of topical diclofenac diethylamine gel in osteoarthritis of the knee. J Rheumatol. 2005;32(12):2384-92.

53. Wadsworth LT, Kent JD, Holt RJ. Efficacy and safety of diclofenac sodium $2 \%$ topical solution for osteoarthritis of the knee: a randomized, doubleblind, vehicle-controlled, 4 week study. Curr Med Res Opin. 2016;32(2):241-50.

54. Bookman AA, Williams KS, Shainhouse JZ. Effect of a topical diclofenac solution for relieving symptoms of primary osteoarthritis of the knee: a randomized controlled trial. CMAJ. 2004;171(4):333-8.

55. Bruhlmann P, Michel BA. Topical diclofenac patch in patients with knee osteoarthritis: a randomized, double-blind, controlled clinical trial. Clin Exp Rheumatol. 2003;21(2):193-8.

56. Waikakul S, Penkitti P, Soparat K, Boonsanong W. Topical analgesics for knee arthrosis: a parallel study of ketoprofen gel and diclofenac emulgel. J Med Assoc Thai. 1997;80(9):593-7.

57. Timmerman L, Stronks DL, Groeneweg JG, Huygen FJ. Prevalence and determinants of medication nonadherence in chronic pain patients: a systematic review. Acta Anaesthesiol Scand. 2016;60(4): 416-31.

58. Park KK, Choi CH, Ha CW, Lee MC. The effects of adherence to non-steroidal anti-inflammatory drugs and factors influencing drug adherence in patients with knee osteoarthritis. J Korean Med Sci. 2016;31(5):795-800.

59. Barbosa CD, Balp MM, Kulich K, Germain N, Rofail D. A literature review to explore the link between treatment satisfaction and adherence, compliance, and persistence. Patient Pref Adher. 2012;6:39-48.

60. Benson MD, Aldo-Benson M, Brandt KD. Synovial fluid concentrations of diclofenac in patients with rheumatoid arthritis or osteoarthritis. Semin Arthritis Rheum. 1985;15(2 Suppl 1):65-7.

61. Fowler PD, Shadforth MF, Crook PR, John VA. Plasma and synovial fluid concentrations of diclofenac sodium and its major hydroxylated metabolites during long-term treatment of rheumatoid arthritis. Eur J Clin Pharmacol. 1983;25(3):389-94.

62. Fowler PD, Dawes PT, John VA, Shotton PA. Plasma and synovial fluid concentrations of diclofenac sodium and its hydroxylated metabolites during once-daily administration of a $100 \mathrm{mg}$ slow-release formulation. Eur J Clin Pharmacol. 1986;31(4): 469-72.

63. Hagen M, Baker M. Skin penetration and tissue permeation after topical administration of diclofenac. Curr Med Res Opin. 2017;33(9):1623-34.

64. Brunner M, Dehghanyar P, Seigfried B, Martin W, Menke G, Muller M. Favourable dermal penetration of diclofenac after administration to the skin using a novel spray gel formulation. Br J Clin Pharmacol. 2005;60(5):573-7.

65. Efe T, Sagnak E, Roessler PP, Getgood A, Patzer T, Fuchs-Winkelmann $S$, et al. Penetration of topical diclofenac sodium $4 \%$ spray gel into the synovial tissue and synovial fluid of the knee: a randomised clinical trial. Knee Surg Sports Traumatol Arthrosc. 2014;22(2):345-50.

66. Miyatake S, Ichiyama H, Kondo E, Yasuda K. Randomized clinical comparisons of diclofenac concentration in the soft tissues and blood plasma between topical and oral applications. Br J Clin Pharmacol. 2009;67(1):125-9.

67. Brune K. Persistence of NSAIDs at effect sites and rapid disappearance from side-effect compartments contributes to tolerability. Curr Med Res Opin. 2007;23(12):2985-95. 
68. Gondolph-Zink B, Gronwald U. Active substance concentrations in articular and periarticular tissues of the knee joint after the cutaneous application of diclofenac diethelammonium Emulgel. Akt Rheumatol. 1996;21:298-304.

69. Davies NM, Anderson KE. Clinical pharmacokinetics of diclofenac. Therapeutic insights and pitfalls. Clin Pharmacokinet. 1997;33(3):184-213.

70. Chan KK, Vyas KH, Brandt KD. In vitro protein binding of diclofenac sodium in plasma and synovial fluid. J Pharm Sci. 1987;76(2):105-8.

71. Gobezie R, Kho A, Krastins B, Sarracino DA, Thornhill TS, Chase M, et al. High abundance synovial fluid proteome: distinct profiles in health and osteoarthritis. Arthritis Res Ther. 2007;9(2):R36.

72. Voltaren Tablets [package insert]. East Hanover: Novartis Pharmaceuticals Corporation; 2011.

73. Flector Patch (diclofenac epolamine topical patch) 1.3\% [package insert]. Bristol: King Pharmaceuticals; 2011.

74. Voltaren Gel [package insert]. Chadds Ford: Endo Pharmaceuticals; 2009.

75. Burian M, Tegeder I, Seegel M, Geisslinger G. Peripheral and central antihyperalgesic effects of diclofenac in a model of human inflammatory pain. Clin Pharmacol Ther. 2003;74(2):113-20.

76. Ku EC, Lee W, Kothari HV, Kimble EF, Liauw L, Tjan J. The effects of diclofenac sodium on arachidonic acid metabolism. Semin Arthritis Rheum. 1985;15(2 Suppl 1):36-41.

77. Ku EC, Lee W, Kothari HV, Scholer DW. Effect of diclofenac sodium on the arachidonic acid cascade. Am J Med. 1986;80(4B):18-23.

78. Liauw $\mathrm{HL}, \mathrm{Ku} \mathrm{E}$, Brandt $\mathrm{KD}$, Benson MD, AldoBenson MA, Waiter SL, et al. Effects of Voltaren on arachidonic acid metabolism in arthritis patients. Agents Actions Suppl. 1985;17:195-9.

79. Martel-Pelletier J, Cloutier JM, Pelletier JP. Effects of aceclofenac and diclofenac on synovial inflammatory factors in human osteoarthritis. Clin Drug Invest. 1997;14(3):226-32.

80. Inoue $H$, Takamori $M$, Shimoyama $Y$, Ishibashi $H$, Yamamoto S, Koshihara Y. Regulation by PGE2 of the production of interleukin-6, macrophage colony stimulating factor, and vascular endothelial growth factor in human synovial fibroblasts. Br J Pharmacol. 2002;136(2):287-95.

81. McDougall JJ, Andruski B, Schuelert N, Hallgrimsson B, Matyas JR. Unravelling the relationship between age, nociception and joint destruction in naturally occurring osteoarthritis of Dunkin Hartley guinea pigs. Pain. 2009;141(3):222-32.

82. Bedson J, Croft PR. The discordance between clinical and radiographic knee osteoarthritis: a systematic search and summary of the literature. BMC Musculoskelet Disord. 2008;9:116.

83. Felson DT, Chaisson CE, Hill CL, Totterman SM, Gale ME, Skinner KM, et al. The association of bone marrow lesions with pain in knee osteoarthritis. Ann Intern Med. 2001;134(7):541-9.

84. Baker K, Grainger A, Niu J, Clancy M, Guermazi A, Crema $M$, et al. Relation of synovitis to knee pain using contrast-enhanced MRIs. Ann Rheum Dis. 2010;69(10):1779-83.

85. Leung YY, Huebner JL, Haaland B, Wong SBS, Kraus VB. Synovial fluid pro-inflammatory profile differs according to the characteristics of knee pain. Osteoarthr Cartil. 2017;25(9):1420-7.

86. Richter F, Natura G, Loser S, Schmidt K, Viisanen H, Schaible HG. Tumor necrosis factor causes persistent sensitization of joint nociceptors to mechanical stimuli in rats. Arthritis Rheum. 2010;62(12): 3806-14.

87. Brenn D, Richter F, Schaible HG. Sensitization of unmyelinated sensory fibers of the joint nerve to mechanical stimuli by interleukin- 6 in the rat: an inflammatory mechanism of joint pain. Arthritis Rheum. 2007;56(1):351-9.

88. Miller RJ, Jung H, Bhangoo SK, White FA. Cytokine and chemokine regulation of sensory neuron function. Handb Exp Pharmacol. 2009;194:417-49.

89. Neogi T, Nevitt MC, Yang M, Curtis JR, Torner J, Felson DT. Consistency of knee pain: correlates and association with function. Osteoarthr Cartil. 2010;18(10):1250-5.

90. French HP, Smart KM, Doyle F. Prevalence of neuropathic pain in knee or hip osteoarthritis: a systematic review and meta-analysis. Semin Arthritis Rheum. 2017;47(1):1-8.

91. Duarte RV, Raphael JH, Dimitroulas T, Sparkes E, Southall JL, Ashford RL, et al. Osteoarthritis pain has a significant neuropathic component: an exploratory in vivo patient model. Rheumatol Int. 2014;34(3):315-20.

92. Fu K, Robbins SR, McDougall JJ. Osteoarthritis: the genesis of pain. Rheumatology (Oxford). 2018;57(suppl_4):43-50.

93. Malfait AM, Schnitzer TJ. Towards a mechanismbased approach to pain management in 
osteoarthritis. Nat Rev Rheumatol. 2013;9(11): 654-64.

94. Muley MM, Reid AR, Botz B, Bolcskei K, Helyes Z, McDougall JJ. Neutrophil elastase induces inflammation and pain in mouse knee joints via activation of proteinase-activated receptor-2. Br J Pharmacol. 2016;173(4):766-77.

95. Borbely E, Sandor K, Markovics A, Kemeny A, Pinter E, Szolcsanyi J, et al. Role of capsaicin-sensitive nerves and tachykinins in mast cell tryptase-induced inflammation of murine knees. Inflamm Res. 2016;65(9):725-36.

96. Lockwood SM, Lopes DM, McMahon SB, Dickenson $\mathrm{AH}$. Characterisation of peripheral and central components of the rat monoiodoacetate model of osteoarthritis. Osteoarthr Cartil. 2019;27(4):712-22.
97. Thakur M, Rahman W, Hobbs C, Dickenson AH, Bennett DL. Characterisation of a peripheral neuropathic component of the rat monoiodoacetate model of osteoarthritis. PLoS One. 2012;7(3): e33730.

98. Sandri A. Spinal antinflammatory action of diclofenac. Minerva Med. 2016;107(3):167-72.

99. Kokki H, Kumpulainen E, Laisalmi M, Savolainen J, Rautio J, Lehtonen M. Diclofenac readily penetrates the cerebrospinal fluid in children. Br J Clin Pharmacol. 2008;65(6):879-84.

100. Okun A, Liu P, Davis P, Ren J, Remeniuk B, Brion T, et al. Afferent drive elicits ongoing pain in a model of advanced osteoarthritis. Pain. 2012;153(4): 924-33. 